\title{
LA LABOR DE TASACIÓN \\ DE LA PROPIEDAD INMOBILIARIA EN TIEMPOS DE CRISIS
}

\author{
ÁNGEL SANZ SARTE* \\ MIGUEL A. ALONSO** \\ ALEJANDRO RUIZ-AYUCAR SEIFERT***
}

En los últimos ocho años hemos vivido lo que muchos consideran la «época dorada» del mercado inmobiliario español. Tiempos en los que el precio de la vivienda ha crecido de manera ininterrumpida en torno a ritmos del $15 \%$ anual. En estos años, la totalidad de los agentes que han intervenido o influido de una forma $u$ otra en el sector inmobiliario (bancos centrales, bancos comerciales, constructoras, promotores inmobiliarios, tasadores de inmuebles y familias), han participado activamente en este crecimiento desmesurado del sector. Todos hemos contribuido a «inflar la burbuja inmobiliaria». ${ }^{1}$

- Por un lado, desde finales de la década de los noventa, los bancos centrales mantuvieron una política monetaria fuertemente expansiva que, creando falsas señales en los mercados, indujo a un excesivo optimismo en empresas y familias. En un contexto de burbuja monetaria, el endeudamiento no

\footnotetext{
* Abogado y Perito Judicial Inmobiliario. Vicepresidente del Grupo Interlex. Email: grupointerlex@gmail.com

** Doctor en Economía y MSc in Economics (Universidad de Essex, Gran Bretaña). Profesor Titular del Departamento de Economía Aplicada I de la Universidad Rey Juan Carlos de Madrid. Email: miguelangel.alonso@urjc.es

*** Notario del Ilustre Colegio de Notarios de Madrid. Email: notario-ruizayucar@ notariado.org

1 Véase en este sentido el excelente informe publicado por Alberto Recarte en Libertad Digital: http://www.libertaddigital.com/fragmentos/recarte-pdf-crisisfinanciera-internacional-crack-financiero-espanol.html
} 
importaba, pues se suponía que los precios de los bienes inmuebles (suelo, viviendas...) siempre subirían y los tipos de interés permanecerían en niveles suficientemente bajos. Marcados por este optimismo artificialmente creado por la abundancia de liquidez, muchas familias y empresas acabaron cayendo en la trampa de un excesivo endeudamiento.

- Por otro lado, la abundancia de crédito barato provocó un exceso de endeudamiento e inversión en el sector de la construcción. Los promotores inmobiliarios acabaron pagando precios excesivos por el suelo, lo que sin duda contribuyó al fuerte crecimiento del precio de la vivienda. No obstante, pese a ser conscientes de los exorbitantes precios pagados, los promotores inmobiliarios incrementaron sustancialmente la oferta de inmuebles en la falsa creencia de que siempre habría demanda para todo lo que se construyera. ${ }^{2}$

- Finalmente, se equivocaron las entidades de crédito, financiando no sólo la compra de viviendas sino también la inversión de las empresas constructoras en condiciones muy ventajosas. El continuo crecimiento en el precio de los activos inmobiliarios (suelo y vivienda), los convertía en un excelente colateral para los préstamos concedidos, incluyendo los préstamos de alto riesgo.

Después de examinar el contexto macroeconómico que indujo a la creación de la burbuja inmobiliaria a finales de la década de los noventa y primeros años del siglo XXI, el presente trabajo trata de analizar el comportamiento de uno de los agentes que intervienen en los procesos de compraventa de inmuebles: los tasadores inmobiliarios, tanto en la fase de «exuberancia irracional» de los últimos años, como en los actuales tiempos de crisis surgidos tras el reventón de la burbuja de precios en el sector de la construcción. Igualmente, pretende determinar qué instrumentos requiere el tasador inmobiliario para, con el ejercicio de

${ }^{2}$ El transcurso del tiempo y el inicio de la crisis hipotecaria, se encargarían de demostrar que en los últimos años la oferta de vivienda tendió a crecer a un ritmo muy superior a su demanda, provocando una acumulación no deseada de stocks que ahora permanece sin vender. 
su profesión, favorecer el buen funcionamiento y la transparencia del mercado inmobiliario, eliminando por otro lado algunos de los procedimientos que han contribuido a inflar la burbuja de precios de la propiedad residencial en los últimos años.

I.

EL CONTEXTO MACROECONÓMICO:

ERRORES DE DECISIÓN, RIESGO MORAL Y BURBUJA INMOBILIARIA

La actual crisis de las hipotecas comienza a gestarse a principios de la década de los noventa, y muy especialmente en los primeros años del siglo XXI. El estallido de la burbuja tecnológica entre 2000 y 2001, y los atentados del 11 de septiembre de 2001, supusieron un clima de inestabilidad que indujo a los principales bancos centrales a expandir las magnitudes monetarias y a bajar los tipos de interés a niveles inusualmente bajos, en un intento de reactivar el consumo y la producción a través de un auge artificial (es decir, no respaldado por una acumulación previa de ahorro) y desmesurado del crédito bancario.

Estos años de expansión crediticia, que en Estados Unidos se habían iniciado con la recesión de 1992 y en Europa años más tarde con la creación de la moneda única, generaron una enorme cantidad de liquidez en los mercados internacionales que distorsionó el proceso de toma de decisiones de los agentes, alterando los criterios de valoración de riesgos de las instituciones bancarias, provocando situaciones de sobreendeudamiento y sobreinversión a todos los niveles (bancos, empresas y familias), y alimentando una burbuja de precios en el sector de las construcción de algunos países desarrollados. La economía de estas naciones entró en una fase de «exuberancia irracional».

En este escenario, los préstamos hipotecarios se concedían sobre la falsa expectativa, espoleada por la propia política expansiva de los bancos centrales, de que: (1) los precios de la vivienda siempre crecerían, por lo que los activos inmobiliarios no sólo eran un objeto de inversión deseable para las familias, sino también un buen colateral para los bancos (incluso en el caso de 
la concesión de hipotecas de alto riesgo); (2) los tipos de interés se situarían permanentemente en los niveles artificialmente bajos - teniendo en cuenta el volumen de ahorro que existía en las economías nacionales- que estaban promoviendo los bancos centrales; y (3) el crédito siempre sería abundante en condiciones muy ventajosas.

Nada hacía presagiar que este escenario cambiaría radicalmente pocos años después: el crédito dejaría de ser abundante hasta llegar al extremo de brillar por su escasez, los tipos de interés se multiplicarían al alza, y los precios de la vivienda entrarían en una etapa de descenso sostenido.

Tan importantes como los errores de decisión generalizados —sobreinversión y sobreendeudamiento- provocados por una mala gestión monetaria, serían los comportamientos de riesgo moral estimulados por la confianza en un rescate masivo del sistema bancario en caso de aflorar problemas de liquidez o de solvencia. ${ }^{3}$ La crisis del sudeste asiático de 1997 ya había demostrado que, bajo un sistema de garantía gubernamental - ya sea explícita o implícita- de los depósitos bancarios, las entidades de crédito reciben fuertes estímulos para perseguir estrategias de préstamo e inversión altamente arriesgadas que, finalmente, pueden precipitar el estallido de una tormenta financiera. ${ }^{4}$

En consecuencia, frente a aquellos que consideran que en la actual crisis de las hipotecas subprime, los mercados financieros han fallado y requieren más regulación, puede oponerse el argumento de que éstos se han movido al son de errores de decisión masivos - provocados por una política monetaria errónea-, y

${ }^{3}$ Habitualmente se utilizan argumentos del tipo «demasiado grande para quebrar» para justificar la existencia de estos rescates financieros masivos. Según este argumento, debe evitarse que ciertas empresas o instituciones financieras quiebren ya que, dado su tamaño, provocarían repercusiones a corto plazo inaceptables sobre la actividad económica de una nación. Sin embargo, la intervención del Estado para solucionar un problema causa la aparición de uno nuevo, en forma de comportamientos de riesgo moral, sin erradicar definitivamente el primero.

${ }^{4}$ En otras palabras, la expectativa de que los estados nacionales acudan al rescate del sistema bancario en caso de crisis, estimula un tipo de comportamientos arriesgados — riesgo moral vinculado al intervencionismo estatal- que finalmente obligan al citado rescate. En consecuencia, la crisis y la posterior intervención estatal que ésta suscita, se convierten en una especie de profecía autocumplida. 
comportamientos de riesgo moral estimulados por una mala intervención, y una peor supervisión, de los estados nacionales en sus correspondientes sistemas financieros en general, y bancarios en particular. ${ }^{5}$

Lejos de la existencia de una regulación financiera insuficiente, en varias economías del mundo desarrollado han fallado los mecanismos de supervisión sobre la actividad de las instituciones de crédito, afectando a la transparencia y, por tanto, al buen funcionamiento de los mercados. Así, durante la fase de exuberancia irracional, los supervisores no hicieron nada por evitar el crecimiento de una serie de mercados y productos financieros que eran completamente opacos a su labor de inspección. ${ }^{6}$

5 En ese sentido, resulta especialmente relevante el artículo publicado por Lawrence H. White en el número de octubre de 2008 de la revista The Freeman: ideas on Liberty, bajo el título «The subprime Crisis Shows that Government Intervenes Too Little in Financial Markets? It Just Ain't so!»

${ }_{6}$ Por otro lado, frente al argumento especialmente extendido de que debe incrementarse la regulación de los mercados financieros internacionales, no debe olvidarse que uno de los gigantes rescatados en la actual crisis de las hipotecas - Fannie Mae- nació en 1937 en el marco de las políticas del New Deal y, aunque en 1968 fue privatizado, siguió manteniendo hasta la fecha la condición de «empresa con patrocinio gubernamental». En 1977, en un intento de igualar y «democratizar» el acceso a la vivienda de todos los norteamericanos, la Community Reinvestment Act promulgada por Jimmy Carter, obligó a las instituciones financieras del país a conceder hipotecas que el mercado se negaba a ofrecer por el bajo rating crediticio de los candidatos. Fue entonces cuando surgieron las hipotecas de alto riesgo bajo los auspicios del gobierno estadounidense. Posteriormente, en 1992, la administración Clinton presionó a Fannie Mae para que relajara aún más las condiciones requeridas para adquirir una hipoteca. Una consecuencia de estas presiones, fue la expansión del mercado secundario de hipotecas de alto riesgo y las titulizaciones de las mismas. Entre 1999 y 2005, bajo la dirección de Franklin D. Raines (designado por Bill Clinton para expandir su objetivo de «vivienda para todos»), Fannie Mae se embarcó en una campaña de crecimiento del crédito hipotecario que ignoraba cualquier principio básico de prudencia. En este contexto, en 2007, Fannie financiaba una de cada cinco hipotecas en Estados Unidos, y a comienzos de 2008 concedía el 80\% de las hipotecas de nueva creación. No puede por tanto negarse, que el mercado de las hipotecas de alto riesgo era conocido y crecía bajo el consentimiento, o cuando menos la apatía, de la administración norteamericana. Bajo esta línea de razonamiento, ¿seguiría siendo entonces sostenible el argumento de que los mercados han fallado? (Los autores agradecen la brillante labor investigadora realizada por Karen Maeyens, en el marco del Master en Economía de la Escuela Austriaca de la Universidad Rey Juan Carlos de Madrid.) 
Por consiguiente, bajo esta interpretación de la crisis, el entorno recesivo al que se ven abocadas las economías del mundo desarrollado en el momento actual, responde a la reacción de los mercados en su intento de detectar y depurar los errores de decisión masivos cometidos en el pasado -durante la fase de exuberancia irracional一, y devolver los precios sobrevaluados de los activos a sus valores reales previos a la formación de la burbuja.

II.

\section{ALGUNAS «IMPRUDENCIAS»EN EL FUNCIONAMIENTO DEL SECTOR INMOBILIARIO ESPAÑOL}

En la última década, a nivel microeconómico, la totalidad de los agentes que han intervenido o influido de una $\mathrm{u}$ otra forma en el sector inmobiliario español, han participado activamente en el crecimiento desmesurado de este sector.

Por un lado, aprovechando una coyuntura especialmente favorable marcada por un fuerte crecimiento de la demanda de vivienda que obtenía financiación bancaria abundante y barata ${ }^{7}$, los propietarios de suelo pusieron a la venta sus propiedades a unos precios artificialmente altos. En este contexto, los promotores inmobiliarios aceptaron estos precios impuestos, ya que hasta el más prudente de ellos sabía que de no entrar en el juego de comprar suelo -aún conociendo que su precio era excesivo- lo haría un promotor competidor, quedando rezagado en la loca carrera por acaparar terrenos. Además, mantenían la ciega expectativa de que sus promociones estarían vendidas en tiempo récord - muchas veces sobre plano-y a unos precios siempre al alza que cubrirían sobradamente el pago del suelo y la construcción de las viviendas, generando unos beneficios adicionales próximos al $40 \%$ de la inversión.

\footnotetext{
7 Además, este fuerte crecimiento de la oferta de financiación en ningún momento fue reflejo de una acumulación de ahorro previa, sino que respondió a la política monetaria excesivamente laxa practicada por los principales bancos centrales. Las fuertes expansiones monetarias orquestadas a lo largo de la última década, habrían provocado errores de decisión masivos a diferentes niveles, «desquiciando» la estructura del proceso productivo de la mayoría de las economías afectadas por la actual crisis hipotecaria, y alimentando una burbuja de precios en el sector inmobiliario.
} 
Dados estos precios, a los compradores de viviendas no les importaba endeudarse desmesuradamente —en muchas ocasiones por encima de su capacidad de ingreso- ya que consideraban su inversión un negocio de rentabilidad segura y continuamente creciente $^{8}$, superior a los intereses exigidos por las entidades bancarias sobre los préstamos concedidos.

Por otro lado, las instituciones de crédito, impulsadas por las políticas de dinero artificialmente barato implementadas por los distintos bancos centrales, accedieron a financiar las compras, tanto de suelo por parte de los promotores inmobiliarios como de vivienda por parte de sus inversores o consumidores finales, basándose en la misma expectativa que los promotores: las viviendas adquiridas experimentarían un rápido crecimiento de valor, suficiente para garantizar la devolución de los préstamos bancarios.

En este entorno, los tasadores inmobiliarios se vieron -y continúan viéndose- permanentemente presionados por parte de los interesados - entidades financieras, vendedores y compradores- para que sus valoraciones, tanto de los terrenos como de las viviendas, sean lo suficientemente altas como para satisfacer los intereses de todos los intervinientes en el mercado.

Por último, los intermediarios no han dudado en incrementar los precios de compraventa con unos honorarios en ocasiones excesivos, lo que ha repercutido en el precio final del producto -la vivienda o el suelo según el caso-.

Todas estas acciones, que aisladamente podrían calificarse de abusos o imprudencias - según el caso- propios de una economía de burbuja, han provocado que el mercado inmobiliario infle artificialmente el valor de los bienes inmuebles. Si bien este hecho no parece haber sido preocupante a los ojos de los agentes económicos (especialmente de los banqueros centrales) en la fase de burbuja de los últimos años, sí parece haber cobrado especial relevancia tras el reventón de la burbuja inmobiliaria y el fuerte descenso de la actividad económica real. Es ahora cuando debe permitirse que el mercado descubra, corrija y depure los errores de inversión cometidos en el pasado - durante la fase

\footnotetext{
8 Dado el incesante crecimiento de los precios de la vivienda.
} 
de exuberancia irracional-, y determine el valor real de los activos hasta ahora sobrevalorados.

III.

UN CASO PARTICULAR: LA LABOR

DE LOS TASADORES INMOBILIARIOS

EN UNA ECONOMIA BAJO EL FANTASMA

DE LA CRISIS INMOBILIARIA Y FINANCIERA

Actualmente, el tasador inmobiliario es un agente fundamental en todo proceso de compraventa de bienes inmuebles ya que, para financiar dichas operaciones, es imprescindible que bancos y cajas de ahorros dispongan de un valor fiable de estos inmuebles. El valor que resulta de la tasación inmobiliaria, será tomado como referencia por las entidades de crédito a la hora de financiar la compraventa y constituir una garantía hipotecaria sobre el inmueble vendido. ${ }^{9}$

En consecuencia, bajo la actual estructura de funcionamiento del mercado inmobiliario español, la función del tasador es primordial. Sin ella, no sería posible establecer un valor de referencia del inmueble que fuese válido y aceptado por todas las partes.

El valor de un bien inmueble varía con el transcurso del tiempo y de las circunstancias coyunturales que existen en el

${ }^{9}$ La labor del tasador inmobiliario es fundamental en el cálculo del llamado loan to value ratio (LTV), que determinará el importe de los préstamos hipotecarios concedidos por la banca en relación al valor de tasación de los inmuebles. El loan to value ratio (LTV), o ratio préstamo-valor de tasación, es la relación entre el importe del préstamo hipotecario y el valor de tasación del inmueble financiado, expresada como un porcentaje. Durante los años de exuberancia irracional, la financiación otorgada por las entidades bancarias españolas para la adquisición de inmuebles fue incrementándose hasta el punto de alcanzar, en algunos casos, una ratio préstamo/valor de tasación de hasta un $110 \%$, cuando lo normal era que se prestase entre el 70 y el $80 \%$ del valor de tasación. Esta práctica no sólo estimuló el crecimiento de la demanda de vivienda, alimentando la burbuja inmobiliaria en nuestro país, sino que facilitó la concesión de préstamos de consumo con garantía hipotecaria (lo que en la literatura anglosajona se denomina mortgage equity withdrawal, $M E W$ ), especialmente extendidos en aquellas naciones que ahora pueden verse más afectadas por un ajuste de su mercado inmobiliario: Estados Unidos, Reino Unido, Australia, Holanda, Dinamarca... 
momento de su tasación. En este sentido, la labor del tasador consiste en determinar el valor de un bien inmueble en un momento determinado y para una finalidad concreta.

Esta labor no es fácil. Hay una serie de circunstancias extrínsecas al propio inmueble que se valora, que influyen determinantemente en el resultado final de la tasación. Estas circunstancias, constituyen una realidad que no puede ser indiferente al tasador, el cual se encuentra con el inconveniente añadido que resulta del hecho de que las diferentes técnicas de valoración, no contemplan por completo todos los componentes extrínsecos que afectan al propio proceso de valoración. Por este motivo, existe un importante componente subjetivo en toda tasación inmobiliaria, independientemente de la normativa y de la técnica o técnicas a aplicar para determinar el valor del inmueble objeto de tasación. Este grado de subjetividad, sólo puede contrarrestarse con la pericia del tasador, es decir, con su experiencia y profundo conocimiento del mercado inmobiliario y de sus circunstancias.

No obstante, dicha subjetividad puede provocar que las valoraciones no se encuentren suficientemente motivadas, especialmente en lo que se refiere a las decisiones tomadas por el tasador siguiendo su criterio y experiencia. Para evitar al máximo posible esta subjetividad, que en cierta medida es inevitable que exista, la obligación del tasador pasa por aplicar unas determinadas técnicas valorativas, dependiendo del bien objeto de tasación y de la finalidad de la misma. Estas técnicas darán lugar a una valoración del inmueble lo más objetiva posible.

Los citados métodos valorativos aparecen recogidos y regulados en la Orden ECO/805/2003, de 27 de mayo, sobre normas de valoración de bienes inmuebles y de determinados derechos para ciertas entidades financieras. Además de los métodos valorativos, la Orden establece cuáles son los principios en los que debe sustentarse la labor del tasador. A modo meramente enunciativo son: el principio de prudencia valorativa, el de mayor y mejor uso $^{10}$, el de sustitución, el de valor residual, el

10 Es decir, el uso más adecuado y financieramente factible que se hace de un bien inmueble dentro de sus posibilidades físicas y legales, que da como resultado el mayor valor del bien. 
de anticipación ${ }^{11}$, el principio de temporalidad, el de finalidad ${ }^{12}$, el de adición y el del mínimo error. El tasador debe guiarse por estos principios a la hora de elaborar la valoración del inmueble.

Asimismo, la Orden establece cuatro métodos a aplicar para la valoración, dependiendo del tipo de inmueble que se trate: método de coste, método de comparación, de actualización de rentas y método residual. Este apartado se centra en el método de comparación, ya que es el más utilizado al ser el adoptado como técnica prioritaria de valoración por la normativa hipotecaria, además de ser considerado el más objetivo y adecuado como indicador de los valores de mercado. Por otro lado, se trata del método más utilizado tanto en el ámbito empresarial, como financiero y de garantías.

$\mathrm{Su}$ funcionamiento aparece descrito en los artículos 22 y siguientes de la Orden ECO 805/2003. Muy resumidamente consiste en, primero, establecer las cualidades y características del inmueble que puedan influir en su valor, y posteriormente seleccionar el segmento del mercado inmobiliario de comparables, procurando obtener precios actuales de compraventa. A continuación, se selecciona una muestra representativa de dichos precios - al menos seis muestras o testigos-, a la que se aplicará el procedimiento de homogeneización necesario, mediante la aplicación de los coeficientes correctores que correspondan, obteniendo así el valor homogeneizado del inmueble.

Conviniendo que el método de comparación es el más objetivo, utilizado y, probablemente, adecuado para la obtención del valor de mercado más factible, la forma de obtener los comparables no deja de quedar bajo la discrecionalidad del tasador, si bien es cierto que guiándose por determinados criterios que se concentran fundamentalmente en la obtención de testigos que sean objetivamente parecidos al inmueble objeto de tasación: metros, localización, calidad de los materiales usados, antigüedad del inmueble, etc.

En la práctica, es la entidad financiera, en nombre de quien solicita la financiación que llevará aparejada la garantía hipotecaria

${ }^{11}$ Valor del inmueble en función de las expectativas de renta que pueda proporcionar en un futuro, retrotraídas al momento presente.

12 Según el cual la finalidad de la valoración condicionará el método a aplicar. 
sobre el inmueble a tasar, quien pide dicha valoración a la sociedad tasadora con la que habitualmente trabaja. La sociedad tasadora, a su vez encarga el trabajo a uno de sus agentes - que, dependiendo de las sociedades, trabajan para éstas como empleados en nómina o como freelance- Parece lógico pensar que el tasador asignado tenga conocimientos exhaustivos de la zona donde se encuentre el inmueble a valorar, pero este extremo no siempre se cumple. Esto puede deberse a diversos motivos: que el tasador asignado tenga una amplia zona de trabajo, que abarque distintos municipios, que haya cambiado de zona, o cualquier otra razón posible. Cuando esto ocurre, y ocurre con bastante frecuencia, el tasador se encuentra en un municipio que le es ajeno y donde no conoce, al menos a priori, las circunstancias particulares que rodean al inmueble a valorar.

En estos casos, la práctica habitual de los tasadores es informarse de las peculiaridades de la zona a través de las inmobiliarias existentes en el municipio o barrio de que se trate, siendo éstas las que informan y facilitan los comparables necesarios para realizar la valoración, además de intentar localizar testigos a través de particulares que anuncien sus inmuebles a la venta. $\mathrm{Al}$ precio que tienen los testigos facilitados por las inmobiliarias, hay que aplicarles una reducción para descontar los costes correspondientes a la comercialización, además de los coeficientes señalados con anterioridad.

Este sistema es el que se utiliza habitualmente para valorar los inmuebles objeto de tasación. El resultado es una valoración que se ajusta razonablemente al precio de mercado. El método de comparación es una técnica muy eficaz en tiempos de bonanza económica, cuando el valor de los inmuebles se revaloriza de forma continua y rápida, ya que los comparables que se toman -incluso en el supuesto de no conocer la zona o municipio donde se encuentre el inmueble a tasar- son perfectamente válidos, considerando que la demanda de viviendas es continua y, por tanto, las compraventas al precio solicitado por la propiedad o la inmobiliaria encargada de la venta son constantes.

El problema surge en un contexto de desaceleración económica y de crisis en el sector inmobiliario, cuando las compraventas 
disminuyen de forma ostensible y existe una volatilidad incontrolada a la baja en los precios de los inmuebles. En otras palabras, en una situación como la actual, como consecuencia de la crisis económico-financiera que sufrimos, no son fiables las referencias que puedan tomarse de las inmobiliarias (o de las ofertas particulares de venta de inmuebles) de la zona donde se encuentre la propiedad a valorar.

No pueden considerarse fiables desde el momento en el que aceptamos que existe un número muy reducido de compraventas, por lo que las ofertas de venta de particulares o en inmobiliarias tienen un «tiempo de espera» (que transcurre desde que el activo se pone a la venta hasta que finalmente se vende) superior, en la mayoría de los casos, a seis meses. Esto quiere decir que el pago que la propiedad pide para proceder a la venta del inmueble, es demasiado alto respecto al precio real de mercado. En época de «vacas gordas» ocurre lo contrario: en general el «tiempo de espera» es bastante corto, lo que significa que la cantidad pedida por la propiedad como precio de venta se acerca bastante al valor real de mercado.

Llegados a este punto, cabe concluir que el «método de comparación» es fiable y objetivo siempre que el mercado inmobiliario se comporte de forma razonablemente estable, de manera que la cantidad de inmuebles demandados y ofertados se aproxime, no transcurriendo mucho tiempo entre la oferta del bien y la venta efectiva del mismo. Sin embargo, cuando se paraliza el mercado como en el momento actual, es muy discutible que pueda aplicarse este método valorativo en una tasación.

IV.

UNA PROPUESTA PARA DOTAR DE MAYOR TRANSPARENCIA AL FUNCIONAMIENTO DEL MERCADO INMOBILIARIO

¿Cuál sería la solución en este caso? A priori la respuesta parece obvia: utilizar un método de valoración alternativo dentro de los contenidos en la Orden ECO/805/2003, relegando el descrito «método de comparación». 
Otra opción sería hacer un uso más riguroso del método de comparación enriqueciéndolo con datos que tengan la mayor fiabilidad, como lo son los precios o valores consignados en las escrituras públicas por las que se transmiten la propiedad de los bienes inmuebles, o se constituyen derechos reales de uso y disfrute sobre los mismos.

No en vano se ha reformado el Reglamento Notarial en fecha bastante reciente en orden a obtener la colaboración de los notarios españoles en iniciativas tan actuales como la lucha contra el fraude o la prevención del blanqueo de capitales (ver Ley 36/2006 de 29 de noviembre). La actuación de los notarios al dar forma a las convenciones jurídicas que afectan a los bienes inmuebles, está en condiciones de servir de filtro para localizar determinadas actuaciones que puedan dar origen a movimientos de capitales opacos o no declarados, y por otra parte, ofrecer una lectura real y fiable del valor actual de los bienes y derechos, en especial en los actos a título oneroso. ${ }^{13}$

Dado que los datos contenidos en las escrituras públicas, como son el precio o el valor de los actos que documentan, se vuelcan a un listado que los notarios confeccionan obligatoriamente y con periodicidad quincenal en el llamado «índice único informatizado", el presente trabajo sugiere que esta información se ponga a disposición de los tasadores inmobiliarios, máxime en estos momentos en los que las operaciones de compraventa se han reducido sustancialmente y, como consecuencia del ajuste del mercado inmobiliario, los precios de la propiedad residencial - sobrevalorados hasta la fecha- tienden a converger hacia su valor real. ${ }^{14}$

${ }^{13}$ El artículo 24 de la citada ley establece que el Notario está obligado a «velar por la regularidad no sólo formal sino material de los actos o negocios jurídicos que autorice o intervenga, por lo que están sujetos a un deber especial de colaboración con las autoridades judiciales y administrativas». En lo que se refiere a las escrituras relativas a transmisión de derechos reales sobre bienes inmuebles a título oneroso, los Notarios quedan obligados a identificar «cuando la contraprestación consistiere en todo o en parte en dinero (...), los medios de pago empleados por las partes.» En este sentido, «deberá identificarse si el precio se recibió con anterioridad o en el momento del otorgamiento de la escritura, su cuantía, así como (especificar si el pago) se efectuó en metálico, cheque, bancario o no, (...) nominativo o al portador, (...) o bien mediante transferencia bancaria».

${ }_{14} \mathrm{El}$ acceso a esta información, favorecería la labor de los tasadores promoviendo la transparencia y el buen funcionamiento del mercado inmobiliario. 
Con las modificaciones introducidas en el Reglamento Notarial —especialmente en su artículo 24-y demás normativa reciente, al estar el Notario obligado a que aparezcan en las escrituras los justificantes de los medios de pago empleados en las compras de inmuebles, ya no hay prácticamente margen a la discrepancia entre el precio realmente pagado y el valor declarado en la escritura, como podía ocurrir en tiempos pretéritos. ${ }^{15}$ En consecuencia, el precio declarado se convierte, a los efectos señalados en este trabajo, en un testigo fiable para posteriores valoraciones.

El único obstáculo es poder acceder a los datos del índice de los Notarios al que en estos momentos solamente tienen acceso las Administraciones, fundamentalmente la tributaria. Es por tanto necesario y urgente dictar las normas necesarias y establecer las cautelas convenientes para facilitar el acceso a esta información, lo que facilitaría el trabajo a los tasadores, y permitiría reducir en gran medida el grado de subjetividad existente en toda valoración al emplearse comparables más precisos y fiables que los facilitados por las inmobiliarias o por los particulares.

Unas tasaciones más precisas repercutirían también en la valoración de los activos inmobiliarios permitiendo con ello, por citar algunos ejemplos, evitar en gran medida las sobrevaloraciones o la falta de transparencia de los mercados inmobiliarios y los llamados «activos tóxicos», en este caso también de origen inmobiliario.

V.

\section{COMENTARIOS FINALES}

En un mundo en el que los agentes económicos deben adoptar decisiones en un entorno de incertidumbre, los precios de mercado son un vehículo de transmisión de información esencial que

${ }^{15}$ El valor declarado en escritura podía estar infravalorado entre un 20 y un $30 \%$ respecto al precio realmente pagado. Esta discrepancia implicaba que los precios reflejados en escritura no podían ser tenidos en cuenta como testigos para posteriores valoraciones puesto que no eran reales, ni tampoco se aproximaban al valor real del inmueble. Por tanto, esta situación no sólo restaba transparencia a las operaciones del mercado inmobiliario, sino que contribuía a inflar los precios de la propiedad inmobiliaria acentuando el clima de burbuja. 
guía las decisiones tanto de productores como de consumidores, haciendo que éstas sean mutuamente compatibles.

Los precios de mercado reflejan los cambios en las valoraciones subjetivas por parte de los consumidores, así como las escaseces relativas de los recursos alternativos. Por tanto, partiendo de la información que ofrecen, los agentes económicos toman decisiones sobre la base de su propio conocimiento, experiencia y expectativas, coordinados en todo momento por los movimientos observados en los precios relativos. De este modo, el sistema de precios de una economía - cuando no está regulado, intervenido o manipulado- se convierte en un elemento esencial de reducción de incertidumbre, que evita la acumulación de errores de decisión.

En consecuencia, partiendo de este razonamiento, el sistema de precios se define como una red de comunicaciones fiable que establece la base para una coordinación económica eficaz, favoreciendo el buen funcionamiento del mercado y de la economía en su conjunto.

En esta línea, el presente trabajo sugiere la adopción de mecanismos que doten de mayor información a los tasadores inmobiliarios para que, en el ejercicio de su trabajo, dispongan de más de instrumentos de decisión que favorezcan el buen funcionamiento y la transparencia del mercado inmobiliario en nuestro país. La existencia de un «índice único informatizado» que informa verazmente del importe de las operaciones de compraventa de bienes residenciales, y la posibilidad de que los tasadores y peritos judiciales inmobiliarios puedan acceder a este registro, pueden ser elementos que contribuyan a reducir el grado de opacidad de las operaciones inmobiliarias, eliminando algunos de los procedimientos que han contribuido a inflar la burbuja de precios de la propiedad residencial en los últimos años. 